\title{
Numerical Analysis on Failure Modes and Mechanisms of Mine Pillars under Shear Loading
}

\author{
Tianhui Ma, ${ }^{1,2}$ Long Wang, ${ }^{1}$ Fidelis Tawiah Suorineni, ${ }^{2}$ and Chunan Tang ${ }^{1}$ \\ ${ }^{1}$ State Key Laboratory of Coastal and Offshore Engineering, Dalian University of Technology, Dalian 116024, China \\ ${ }^{2}$ School of Mining Engineering, Faculty of Engineering, UNSW Australia, Sydney, NSW 2051, Australia \\ Correspondence should be addressed to Tianhui Ma; tianhuima@dlut.edu.cn
}

Received 13 January 2016; Accepted 11 April 2016

Academic Editor: Marcin A. Lutyński

Copyright (c) 2016 Tianhui Ma et al. This is an open access article distributed under the Creative Commons Attribution License, which permits unrestricted use, distribution, and reproduction in any medium, provided the original work is properly cited.

\begin{abstract}
Severe damage occurs frequently in mine pillars subjected to shear stresses. The empirical design charts or formulas for mine pillars are not applicable to orebodies under shear. In this paper, the failure process of pillars under shear stresses was investigated by numerical simulations using the rock failure process analysis (RFPA) 2D software. The numerical simulation results indicate that the strength of mine pillars and the corresponding failure mode vary with different width-to-height ratios and dip angles. With increasing dip angle, stress concentration first occurs at the intersection between the pillar and the roof, leading to formation of microcracks. Damage gradually develops from the surface to the core of the pillar. The damage process is tracked with acoustic emission monitoring. The study in this paper can provide an effective means for understanding the failure mechanism, planning, and design of mine pillars.
\end{abstract}

\section{Introduction}

Studies on pillar size and stability have been conducted for many years. The main research methods include the safety factor, probabilistic analysis, numerical modeling, empirical methods, and physical testing methods. Brady et al. [1] developed a pillar strength formula accounting for pillar size and geometry based on the existing representative design theory for pillar spacing. Bieniawski [2] considered that the compressive strength of coal cubes (short-term strength) decreases with an increase in size and reaches an asymptotic value at a cube size of about $1.5 \mathrm{~m}$ which, according to him, was the critical size for coal. Lunder and Pakalnis [3] considered the role of confinement in hard rock pillar strength. González-Nicieza et al. [4] proposed a new formula considering Bieniawski's rock mass quality classification and the shear-resistance safety factor of pillars. Esterhuizen [5] investigated some of the issues affecting pillar strength at low width-to-height ratios in hard brittle rock and concluded that the strength of slender pillars was more variable than that of wider pillars. Mortazavi et al. [6] suggested that, at high WH ratios, pillars behave in a very stiff manner in the elastic range, demonstrating a high load-bearing capacity. Esterhuizen et al. [7] developed a pillar strength equation based on stable and failed pillars observed. Ghasemi and Shahriar [8] proposed a new coal pillar design method. Suorineni et al. $[9,10]$ developed new knowledge on why pillars in ore bodies in shear are more prone to catastrophic failures than would normally be expected. They introduced the concept of shear loading in orebodies and pillars.

Many scholars in China have carried out in-depth studies on pillar stability. Liu and $\mathrm{Xu}$ [11] estimated rock mass strength for the gob area of a phosphate mine according to rock mass classification, analyzed stability of pillars in the gob area using the safety factor and reliability analysis methods, and represented the safety factor of pillars by the average safety factor. Yang [12] proposed a new design method for pillar spacing, which has been applied effectively in engineering practice. Wang and $\mathrm{Li}$ [13] proposed the concept of shear-resistance safety factor for mine pillars, considering that pillars generally fail in shear. They suggested that pillars were safe and reliable when the shear-resistance safety factor was greater than 1.2. Wang et al. [14] proposed a formula for pillar width for deep stope mining and suggested 
that the key factors affecting the proper pillar width were the stopping span and depth. The relevant theory was verified by field tests.

In summary, proper pillar design is the key to prevention of pillar failure and reduction of related accidents [15]. Pillar design is mostly based on empirical formulas, limit equilibrium, loading theory, and other analysis methods [12, $16]$ at present. Due to differences in geological conditions in various regions and complex mining conditions, the abovementioned methods are not optimized approaches for the design of pillars. Small pillar sizes would lead to surface subsidence and affect the stability of mines, while too thick pillars lead to waste of resources [17]. In this study, the rock failure process analysis program, RFPA2D [18-21], was used to simulate pillars of various sizes and to investigate the failure mechanisms. The simulation results provide further understanding of pillar mechanics and can be used for safer design and construction of underground mine pillars.

\section{Principles of RFPA}

When rock is under load, it continuously gets microcracks after a certain stress level resulting in nonlinear deformation. The development and the accumulation of these microcracks eventually lead to a final macrofailure of the rock. The nonlinear deformation of rocks can be simulated with Finite Element Method (FEM), but it only stays on macrodeformation of the rocks; it cannot describe the development of the microcracking process leading to the formation of the macrofailure plane formation. In order to simulate the process of rock failure, many numerical modeling methods such as Finite Difference Method (FDM), Boundary Element Method (BEM), Half Analytical Element Method (HAEM), Discrete Element Method (DEM), and Extend Finite Element Method (EFEM) have been applied for fully solving some difficult rock engineering problems. These methods still have many imperfections, for instance, problems of nonlinearity and discontinuities of rocks, problems relating the effects of step excavation, and backfill practice on stability of rock masses. To solve these problems, in 1995, a new numerical modeling method referred to as rock failure process analysis (RFPA) was developed to conduct stress analysis based on Finite Element Method and nonlinearity, nonhomogeneity, and the anisotropic properties of rocks. The RFPA code has several special features:

(1) The macrofailure is an accumulation of microdamage. Elastic-brittle constitutive criterion is applied to each element. When the stresses of some elements reach peak strength, failure occurs. By this method, physically discontinuous problems can be resolved with continuum mechanics.

(2) Heterogeneity of rock is accounted for in the elements using Weibull distribution in the code for modulus of elasticity, strength, and some other parameters of the elements.

(3) Acoustic emission associated with the progressive failure process is included in the code by recording the event-rate of failed elements.

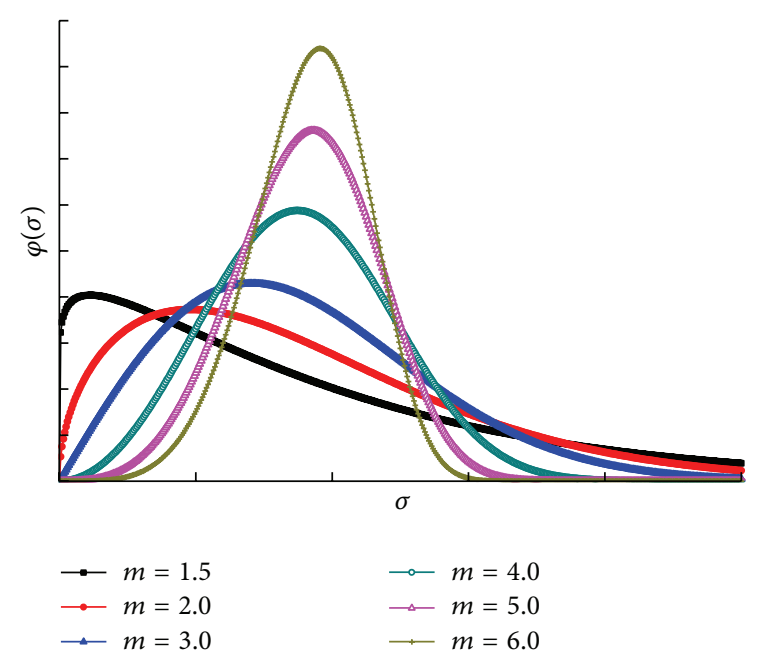

FIgURE 1: Weibull distribution for mechanical properties of rock materials with different homogeneity indices $m$.

In RFPA2D, Weibull statistical distribution is introduced to describe the discrete physical-mechanical property as in the following formula:

$$
\varphi(\sigma)=\frac{m}{\sigma_{0}}\left(\frac{\sigma}{\sigma_{0}}\right)^{m-1} \exp \left[-\left(\frac{\sigma}{\sigma_{0}}\right)^{m}\right] .
$$

In the formula, $\sigma$ is a parameter for one element, $\sigma_{0}$ is the mean value of the same parameter for all the elements in one grain, and $m$ is a shape parameter. The shape parameter $m$ is defined as the homogeneity index of the rock.

For a practical rock material, the type of the statistical distribution needs to be determined in the laboratory. At this time, we assume the physical-mechanical properties of the elements follow (1). A larger $\mathrm{m}$ implies a more homogeneous material and vice versa. Figure 1 shows the shape of the probability density function for various homogeneity indices.

Once the material fails, the mechanical property and the ability to bear load will be changed. Usually, the change is a degradation process, that is, reduction of the physical-mechanical property parameter. Based on the above-mentioned theory, RFPA2D deals with element failure by introducing degradation of the element property. When the stresses in some elements satisfy the Mohr-Coulomb shear failure criterion or maximum tensile strain criterion, the element is damaged and becomes weak according to the rules specified by the strength criterion. The stress and deformation distributions throughout the model are then adjusted instantaneously after each rupture to reach the equilibrium state. The stresses in some elements might be increased due to stress redistribution. These updated stresses may exceed the critical value specified by the strength criterion. Further ruptures may, therefore, be caused. The process is repeated till no stable elements are present. By this way, the continuous media mechanics method can be used to deal with the discontinuous problem. And the Finite Element Method can be used to simulate the whole failure process of rock material from deformation, microfailure to macroscopic failure. 


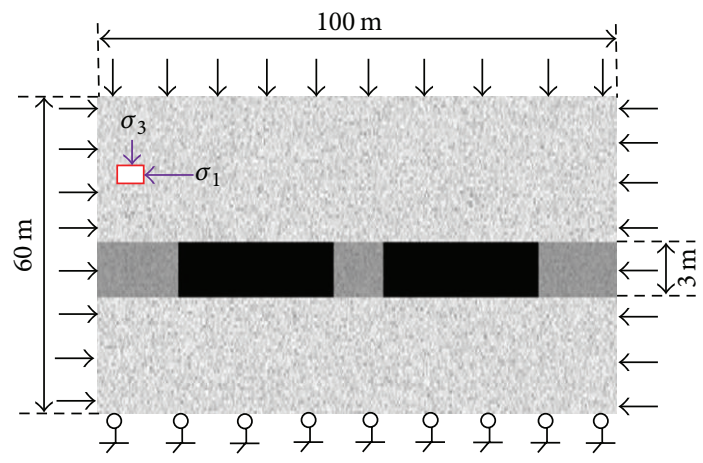

FIgURE 2: Numerical model and boundary condition.
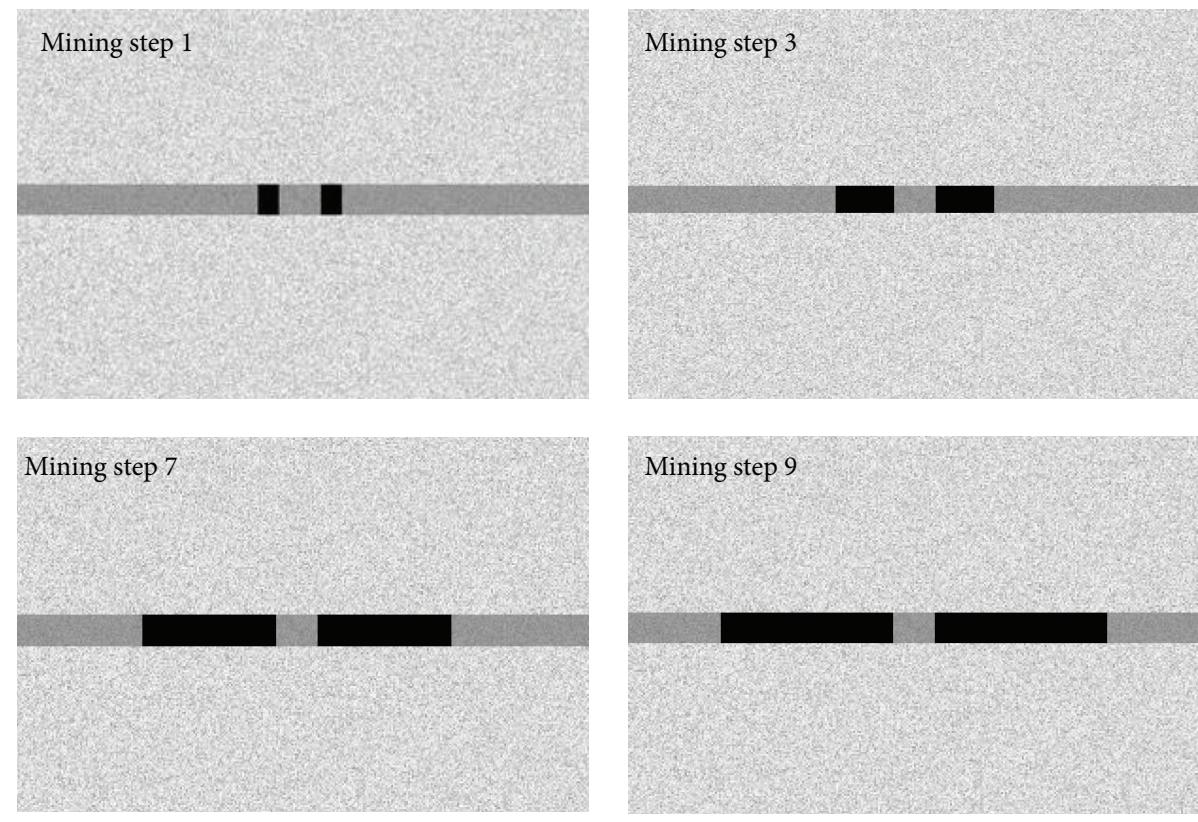

FIGURE 3: Mining sequence and pillar geometry within the RFPA2D model.

\section{Numerical Modeling of Pillars Using RFPA}

3.1. Model Overview. Following the procedure used by Suorineni et al. $[9,10]$ the effects of pillar dip angle, widthto-height ratio, and a certain stress ratio on the stability of pillars in a room-and-pillar mine are investigated using five width-to-height ratios, namely, $0.5,1.0,1.5,2.0$, and 2.5 , at various degrees of orebody inclination, namely, $0^{\circ}$ (Horizontal orebody resulting in vertical pillars), $10^{\circ}, 20^{\circ}$, $30^{\circ}$, and $40^{\circ}$ (orebody dip angles result in inclined pillars). A typical numerical model setup in RFPA2D is shown in Figure 2. For comparative analysis of the impact and role of various factors, the extraction ratio is kept constant at $75 \%$ in accordance with Suorineni et al. [10]. The model dimension is $100 \mathrm{~m} \times 60 \mathrm{~m}$. The height of orebody is $3 \mathrm{~m}$. The model consists of $500 \times 300=150000$ elements. The loading was applied in three stages. Firstly, loading was applied in both $X$ and $Y$ directions at $k_{o}$ ratios of $0.5,1.0,1.5$, and 2.0. Then, the stress in the $X$ and $Y$ directions remained unchanged and the excavation steps were carried out as shown in Figure 3 until the extraction ratio of $75 \%$ is reached for the given pillar size. After finishing all the excavation steps, the loading in the $X$ direction remained unchanged, and the loading in the $Y$ direction was gradually increased until failure. The loading was increased by $0.2 \mathrm{MPa}$ per step.

3.2. Model Input Mechanical Parameters. The strength and elastic modulus of each element were assigned according to the Weibull distribution so as to reflect the rock mass heterogeneity. The coefficient $m$ reflects the degree of homogeneity of rock mass properties. The higher the coefficient $m$ is, the more homogeneous the rock mass properties are; the smaller the coefficient $m$ is, the more heterogeneous the rock mass properties are. The coefficient $m$ is determined by an empirical formula [22]:

$$
\begin{aligned}
& \frac{\sigma_{c}}{\sigma_{0}}=0.85298-0.80668 \exp \left(-\frac{m}{10.68877}\right) \\
& \frac{E_{c}}{E_{0}}=1.02453-0.62081 \exp \left(-\frac{m}{2.59074}\right),
\end{aligned}
$$


TABLE 1: Mechanical properties of the model.

\begin{tabular}{|c|c|c|c|c|c|}
\hline Parameter & $\begin{array}{c}\text { Coefficient of } \\
\text { homogeneity }(m)\end{array}$ & $\begin{array}{l}\text { Uniaxial compressive } \\
\text { strength }\left(\sigma_{c}\right) / \mathrm{MPa}\end{array}$ & Elastic modulus $\left(E_{c}\right) / \mathrm{MPa}$ & Poisson's ratio $(\nu)$ & $\begin{array}{l}\text { Angle of internal } \\
\text { friction }(\varphi) /^{\circ}\end{array}$ \\
\hline Rock mass & 4 & 170 & 70000 & 0.25 & 40 \\
\hline Orebody & 7 & 60 & 20000 & 0.22 & 35 \\
\hline
\end{tabular}

where $\sigma_{c}$ and $E_{c}$ are, respectively, the simulated uniaxial compressive strength and the elastic modulus and $\sigma_{0}$ and $E_{0}$ are, respectively, the characteristic compressive strength and the characteristic elastic modulus of mesoscopic elements. According to the real mechanical parameters of rock masses in a mine, the macroscopic parameters can be converted to mesoscopic element parameters according to the above empirical formulas. The material parameters for the rock masses and orebody in the model are listed in Table 1.

\section{Simulation Results and Analyses}

4.1. Failure Characteristics of Vertical Pillars with Different Width-to-Height Ratios. Mine pillars are in situ rock left after mining to ensure mine safety. The determination of pillar sizes dictates the cost of mining and mine safety. Pillar instability refers to the compressional-shear or splitting failure under uniaxial stresses when external loading reaches a limit value. Upon failure, the pillar loses its bearing capacity and can no longer transfer stresses from the overlying strata [17] to the floor.

Accompanying these damage processes, an elastic stress wave is generated, which travels from the point of origin within the rock to a boundary, where it is observed as an acoustic emission signal [23]. In rock, acoustic emission is generated by crack formation under high stress [24]. This phenomenon provides a basis for a method which is able to detect zones of microcracking or macrocracking or highly stressed zones in rock without any knowledge of the mechanical properties or the state of stress [24]. Currently, acoustic emission is the most direct method to monitor and predict the process of rock burst [25]. This study mainly focuses on pillar rock burst. Here, only the failure processes of pillars with various sizes under various $k_{o}$ pressures of 0.5 , $1.0,1.5$, and 2.0 are presented. In the plot of acoustic emissions, the size of circles represents the magnitude of energy released during acoustic emissions, and the number of circles indicates the amount of acoustic emissions. As shown in Figure 4, the location of pillar monitoring point was set at pillar midheight.

Figure 6 shows the corresponding shear stresses to the various loading stages in Figure 5. As shown in Figures 5 and 6 , at the initial loading stage, since the loading is low no acoustic emission is observed (Figure 5(a)) and only a few microcracks appear at some locations where the compressive strength is low or tensile stress is high and a small amount of acoustic emissions is detected (Figure 5(b)). The microcracking gradually propagates towards the pillar surface and tends to develop towards the four corners (Figure 5(b): step 82-1). At this point, cracks have not coalesced yet and the pillar still has certain support capacity. With further increase in load, the axial stress in the pillar increases and microcracks in the

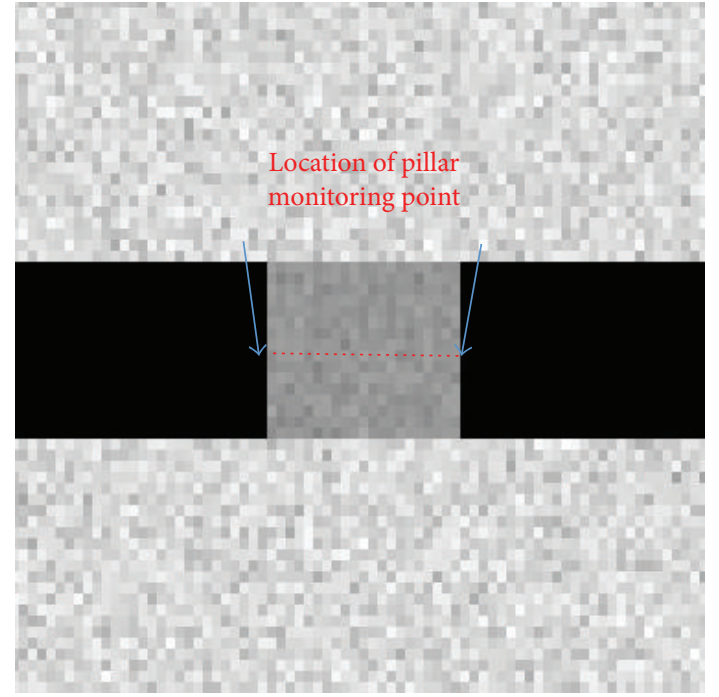

FIGURE 4: Location of stress and deformation monitoring points.

pillar propagate and coalesce as shown in Figure 5(c). Figures 5 and 6 both show that a shear failure zone is eventually formed in the pillar and the pillar is completely failed (Figures 5(c) and 6(c)).

The corresponding stress-strain curve to the loading steps in Figures 5 and 6 is shown in Figure 7 . Figure 7 shows that the stress-strain curve is approximately linear up to the point of failure. The figure shows that the maximum average axial stress in the pillar is $32.8 \mathrm{MPa}$. This is the pillar strength. The figure also shows that the pillar has a residual strength of about $12.5 \mathrm{MPa}$.

As shown in Figures 8, 9, 11, and 12 microcracks propagate more from the outside of the pillar towards the pillar core and the bearing capacity also increases with increasing pillar size as shown in Figures 7, 10, and 13. In these figures the pillar strengths are $32.8 \mathrm{MPa}, 33.2 \mathrm{MPa}$, and $34.2 \mathrm{MPa}$ for pillar $W / H$ ratios of $0.5,1$, and 1.5 , respectively.

When the width-to-height ratio is 2.0, a small amount of acoustic emissions and microcracks occurs first at the pillar corners (Figure 14(b)) and increases towards the centre of the pillar as shown in Figure 14(c) where there is a great amount of acoustic emissions occurring at that loading stage, indicating that the pillar has reached its ultimate support capacity. It can be seen from the corresponding stress-strain curve shown in Figure 16 that the average pillar strength is 43.4 MPa. As shown in Figure 14(c), cracks are formed on the pillar surface and coalesce at the central region, leading to formation of a compressive failure zone. Figure 15 shows plot of shear stresses around a pillar with width-to-height ratio = 2.0 . 


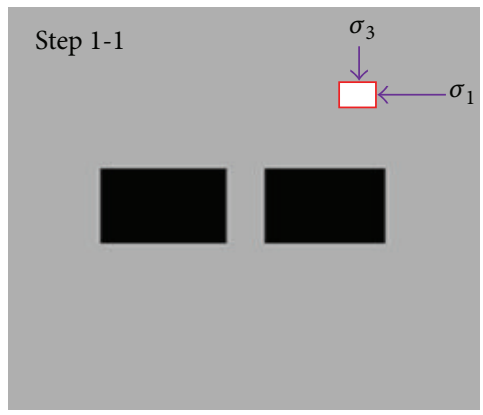

(a)

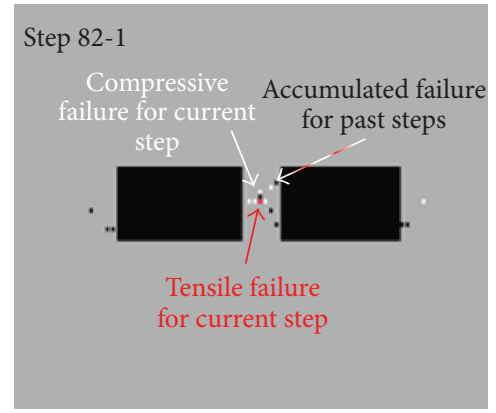

(b)

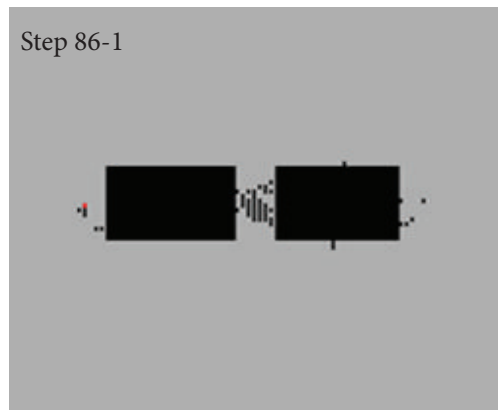

(c)

FIGURE 5: Plot of acoustic emissions for a pillar with width-to-height ratio $=0.5$.

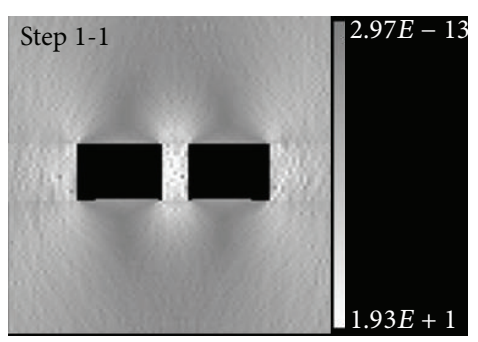

(a)

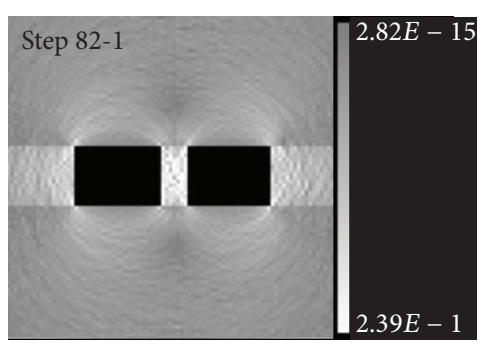

(b)

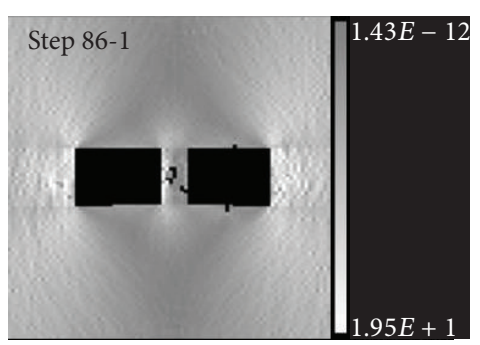

(c)

FIGURE 6: Plot of shear stresses around a pillar with width-to-height ratio $=0.5$.

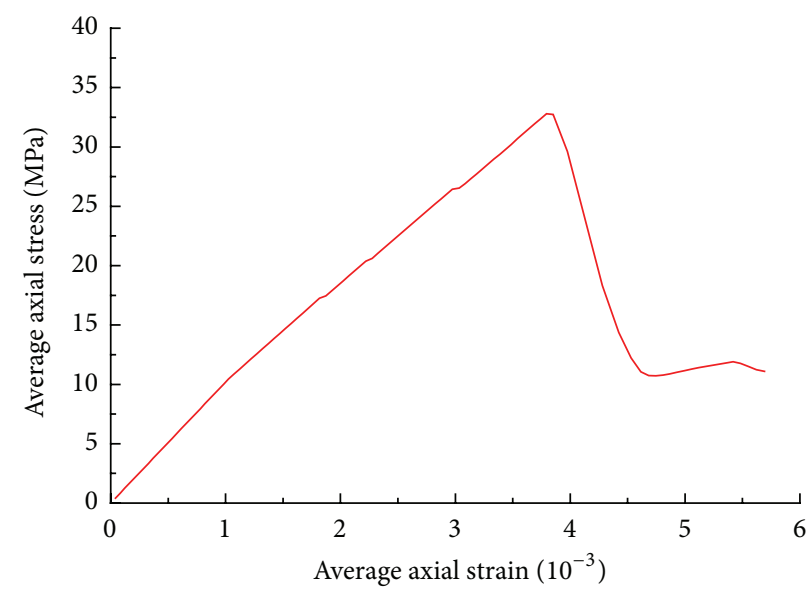

FIgURE 7: Average axial stress-strain curve for a pillar with width-to-height ratio $=0.5$.

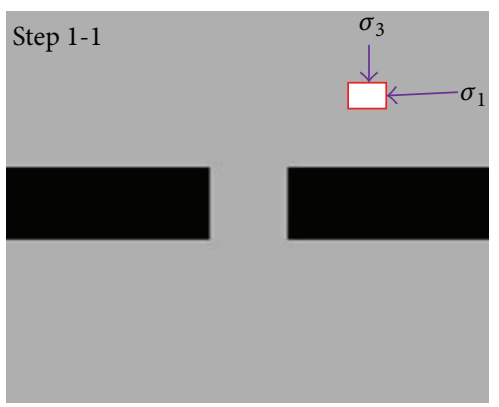

(a)

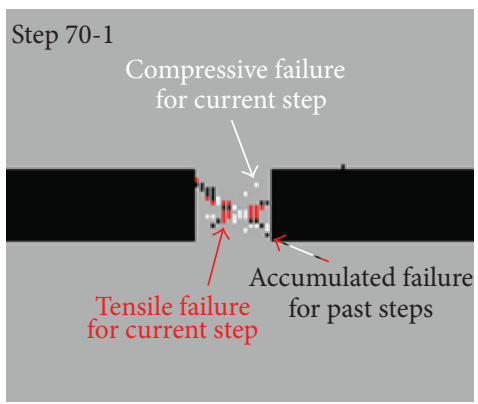

(b)

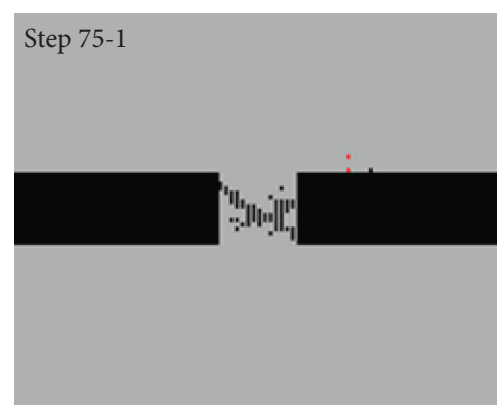

(c)

FIGURE 8: Plot of acoustic emissions for a pillar with width-to-height ratio $=1.0$. 


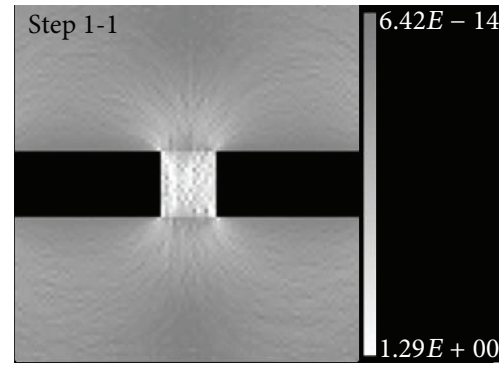

(a)

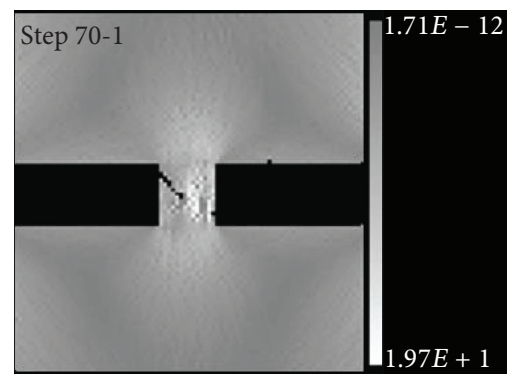

(b)

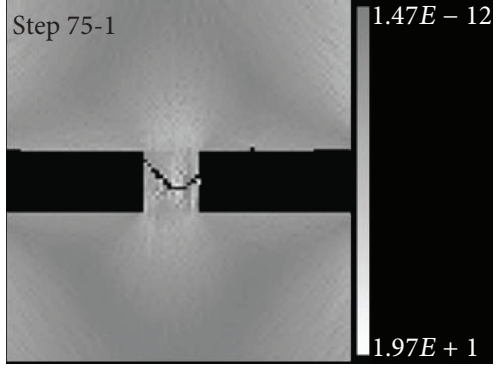

(c)

FIGURE 9: Plot of shear stresses around a pillar with width-to-height ratio $=1.0$.

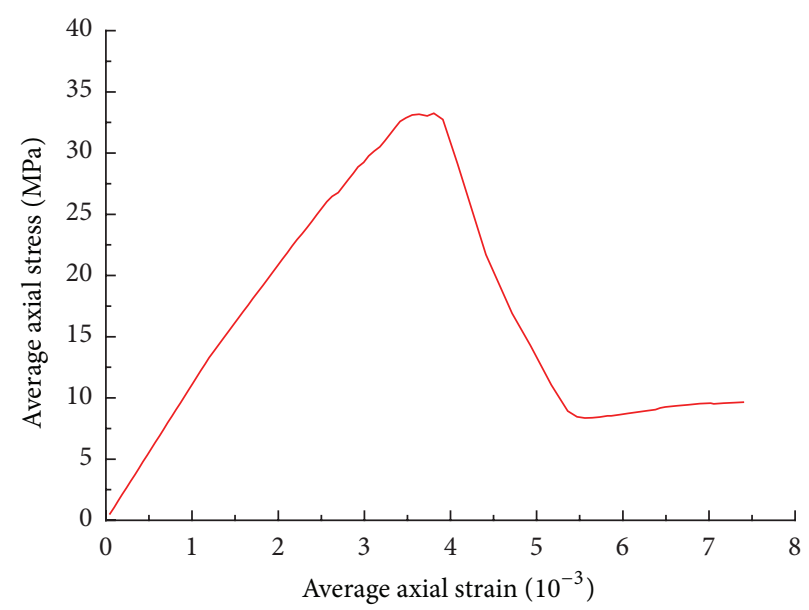

Figure 10: Average axial stress-strain curve for a pillar with width-to-height ratio $=1.0$.

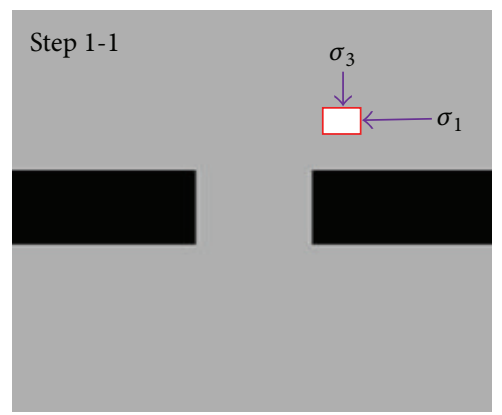

(a)

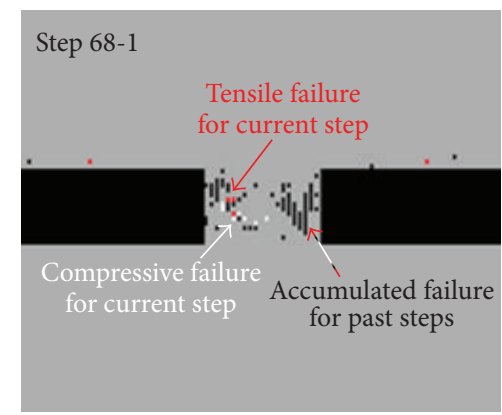

(b)

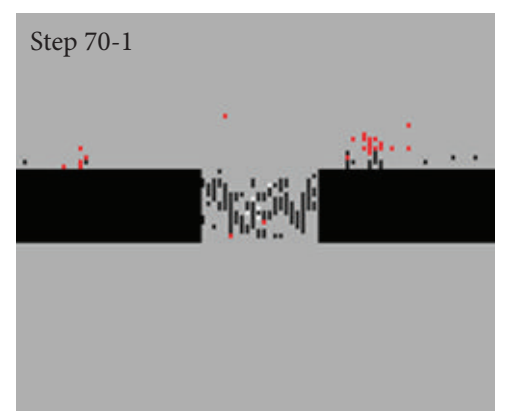

(c)

FIgURE 11: Plot of acoustic emissions for a pillar with width-to-height ratio $=1.5$.

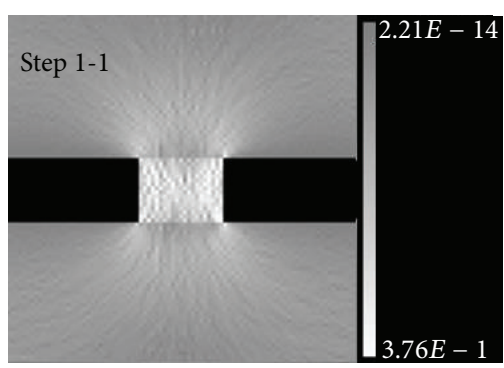

(a)

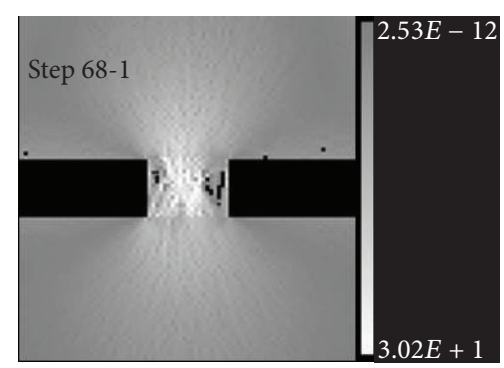

(b)

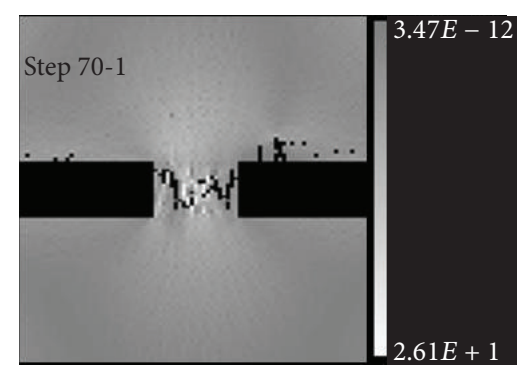

(c)

Figure 12: Plot of shear stresses around a pillar with width-to-height ratio $=1.5$. 


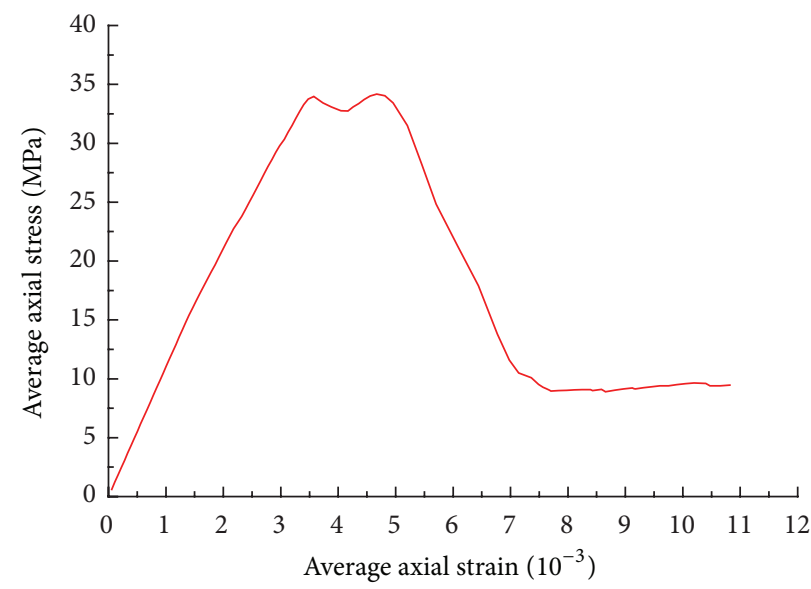

FIGURE 13: Average axial stress-strain curve for a pillar with width-to-height ratio $=1.5$.

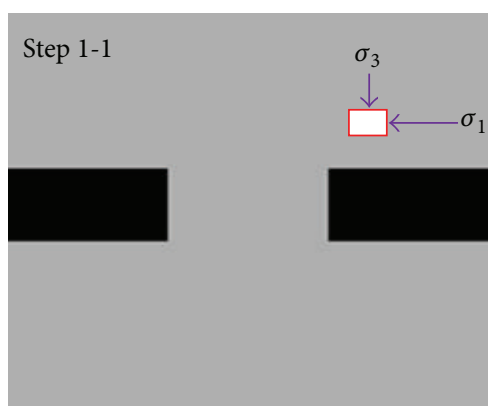

(a)

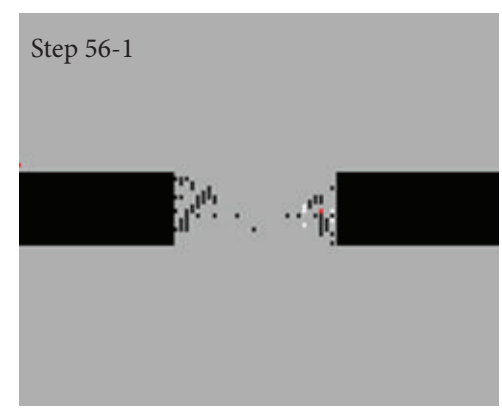

(b)

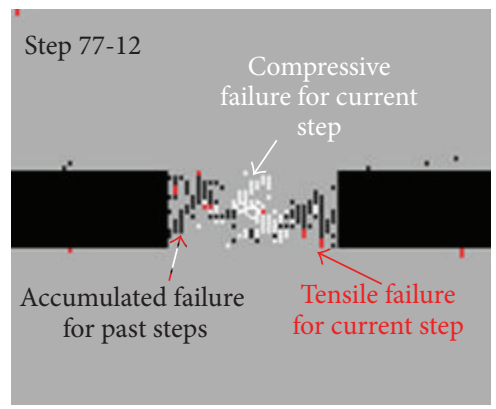

(c)

Figure 14: Plot of acoustic emissions for a pillar with width-to-height ratio $=2.0$.

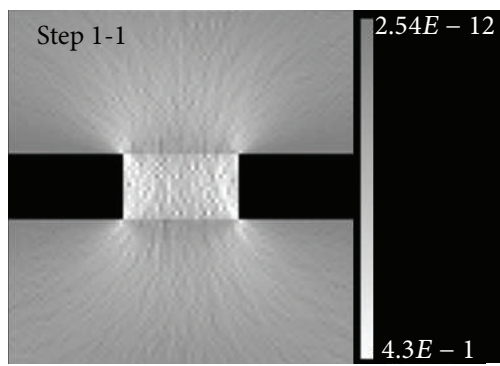

(a)

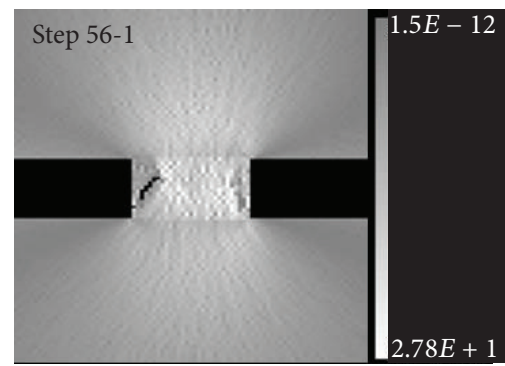

(b)

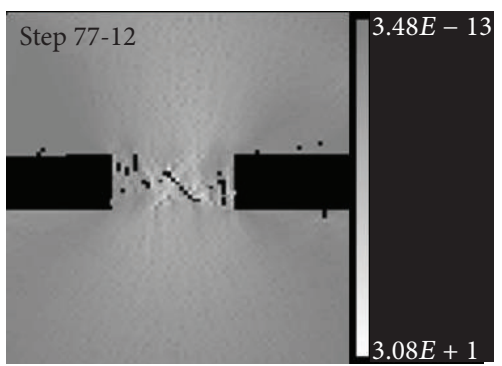

(c)

FIGURE 15: Plot of shear stresses around a pillar with width-to-height ratio $=2.0$.

As can be seen from Figures 17 and 18, the failure modes of the pillars with width-to-height ratios of 2 and 2.5 are similar. The average pillar strength is $44.9 \mathrm{MPa}$ for the pillar $\mathrm{W} / \mathrm{H}$ ratio of 2.5 indicating an increased pillar strength by $3.4 \%$ compared to the case with $W / H=2.0$ (Figure 19).

The simulation results indicate that, with increasing pillar size, shear band failure from the surface to the interior is the main failure mode. Elastic stresses start to build up at the pillar edges and stress concentration rises at these points, and the pillar edge failure leads to stress concentration shifting towards the pillar core. Therefore, failure first occurs on the pillar surface and gradually develops towards the core of the pillar.
4.2. Effects of Various Pillar Inclinationson Pillar Strength. As shown in Figure 20, the pillar strength increases with increasing width-to-height ratio. When the orebody is horizontal, the strength that the pillar can sustain is higher than that in case of an inclined orebody and confirms the findings by Suorineni et al. [10].

Generally speaking, larger rocks contain greater amount of weak structural planes, which is the main cause of lower pillar strength for the pillar with certain width-to-height ratio. Hence, the bearing capacity of the pillar increases and then keeps constant when the width-to-height ratio increases to enough large value (the height remains constant). 


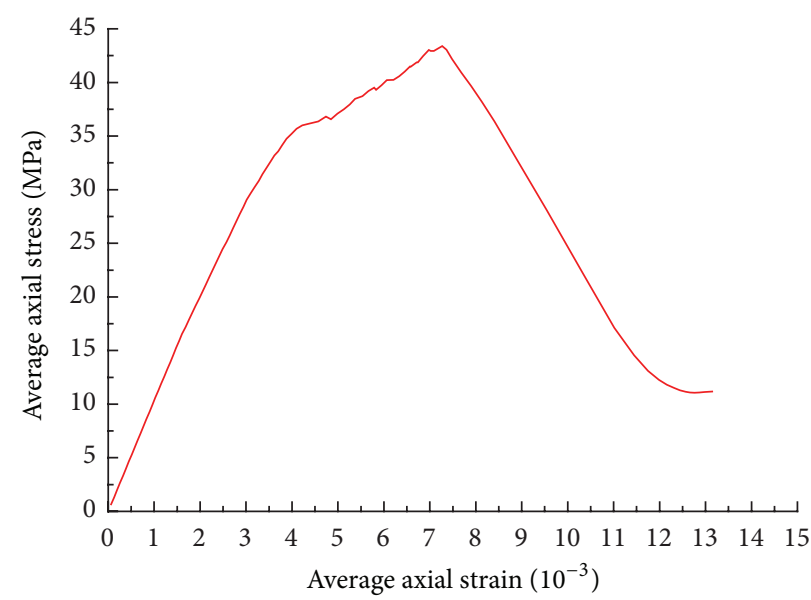

FIgURE 16: Average axial stress-strain curve for a pillar with width-to-height ratio $=2.0$.

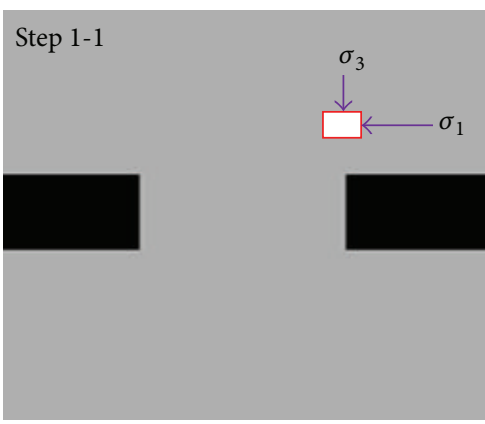

(a)

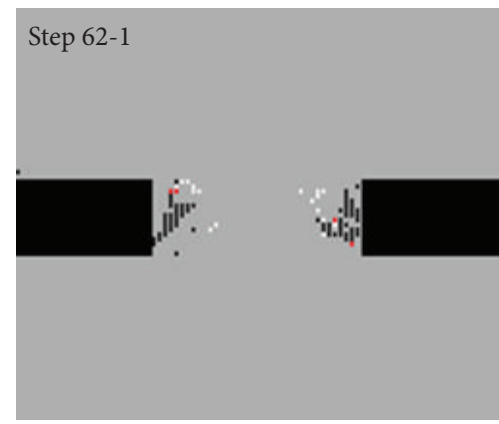

(b)

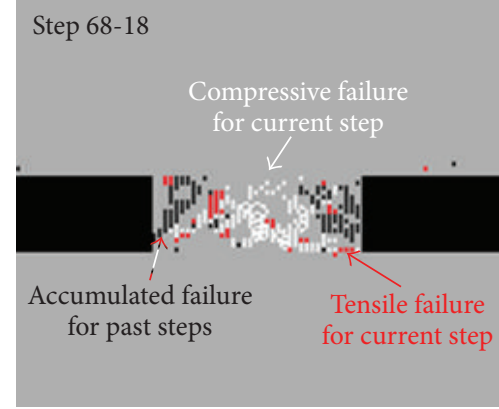

(c)

FIGURE 17: Plot of acoustic emissions for a pillar with width-to-height ratio $=2.5$.

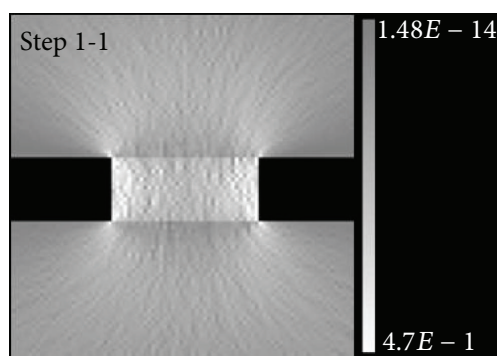

(a)

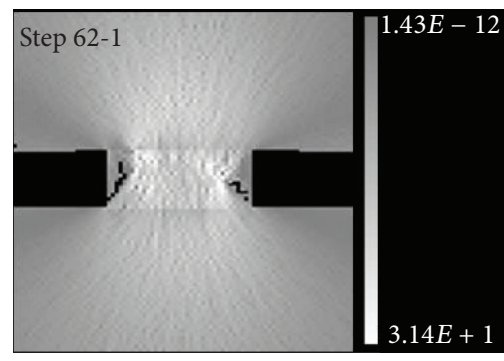

(b)

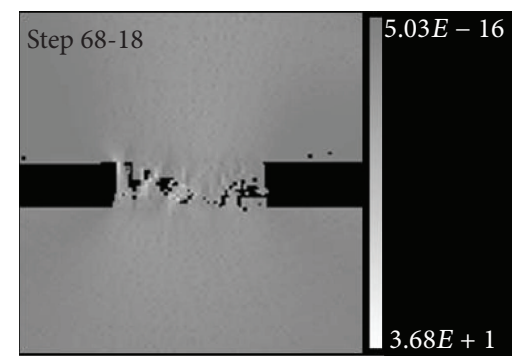

(c)

FIGURE 18: Plot of shear stresses around a pillar with width-to-height ratio $=2.5$.

For the pillar with the width-to-height ratio of 2.0 under various $k_{o}$ pressures, the principal stress difference and axial displacement are plotted in Figure 21.

As known from triaxial compression tests, brittleness and plasticity are not intrinsic properties of rock, instead, dependent on the stress state. Rock brittleness and plasticity can be converted with each other with changing stress state $k_{o}$ [26]. It can be seen from Figure 21, when the pressure ratio $k_{o}$ is equal to 2.0 , the principal stress difference increases to a peak value first and then drops rapidly. The failure mode of the pillar is brittle failure. With decreasing the pressure ratio $k_{o}$, the stress curves become gentle, indicating that plasticity is more dominant. Therefore, the failure mode of the pillar is plastic failure when the pressure ratio $k_{o}$ decreases. The higher the pressure ratio $k_{o}$ is, the more prominent the brittle failure characteristics are.

4.3. Pillar Stresses in Inclined Pillars. When mine pillars have sharp corners stress concentration usually occurs at the sharp corners. Hoek and Brown [27] suggest that in calculating average pillar stresses the corner stresses should be ignored. In this paper, the stresses and failure process of pillars at various dip angles are simulated using the RFPA2D program. The major principal stresses $\sigma_{1}$ on the two diagonals and the 


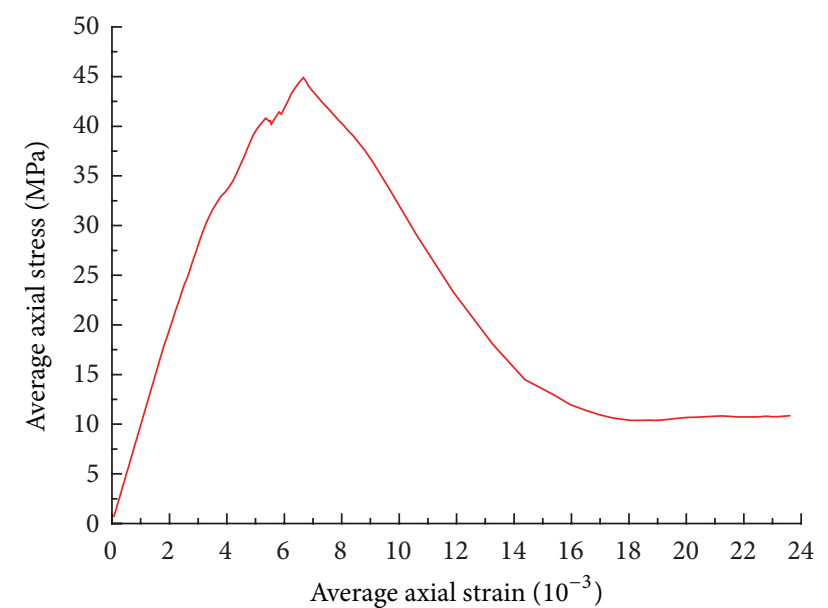

FIGURE 19: Average axial stress-strain around a pillar with width-toheight ratio $=2.5$.

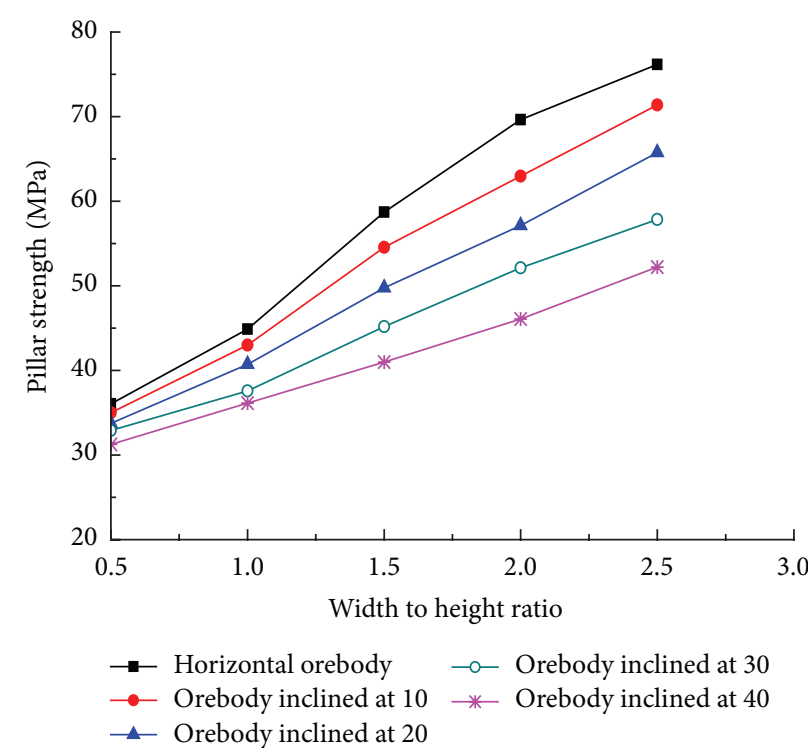

FIGURE 20: Pillar strength at various inclinations for various widthto-height ratios for $k_{o}$ of 1.5 .

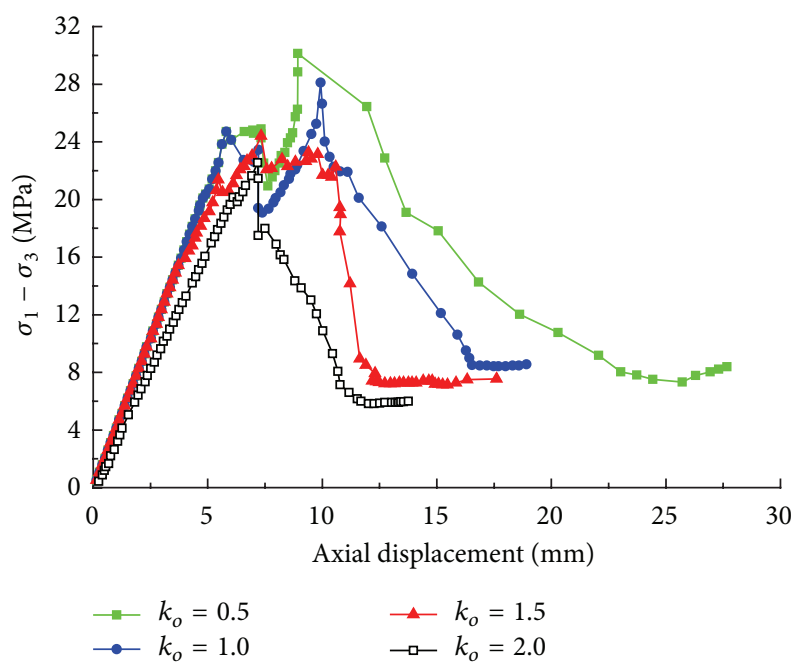

FIGURE 21: Variations of principal stress difference with axial displacement for various pressures ratios, $k_{o}$.

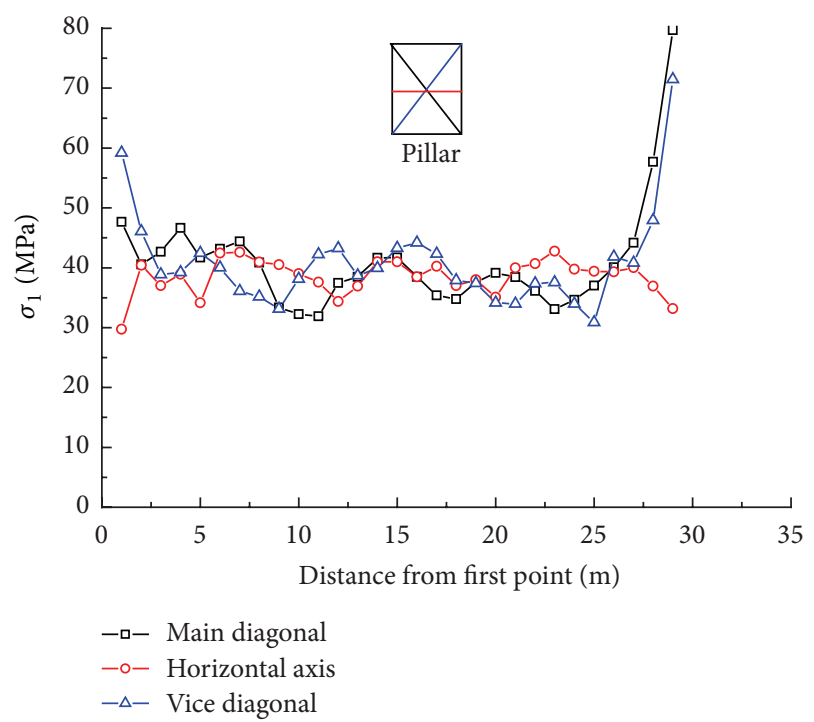

FIGURE 22: Variation of $\sigma 1$ with distance from the first point (dip angle $=0^{\circ}$ ).

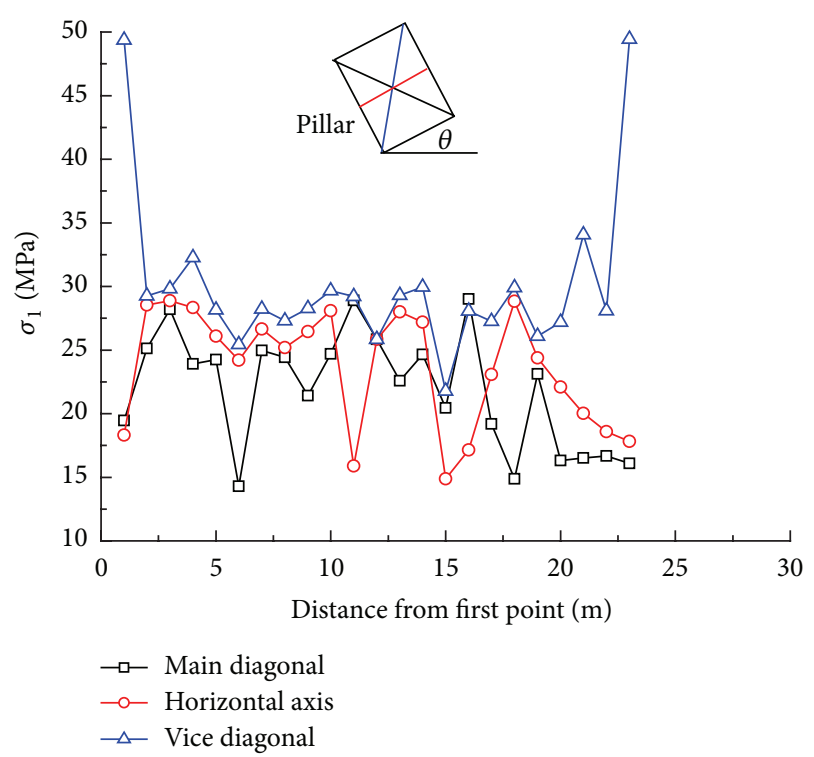

FIGURE 23: Variation of $\sigma 1$ with distance from the first point (dip angle $=10$ ).

horizontal axis at midheight of the pillar are plotted as shown in Figures 22 and 23 for a vertical pillar and an inclined pillar, respectively.

As can be seen from Figures 22 and 23, stress concentration occurs in the four corners of the pillar. In order to better explain microcracking initiated at the four corners, acoustic emissions in a pillar with a width-to-height ratio of 2.0 under the pressure ratio $k_{o}$ of 1.0 are shown as an example.

It can be seen from Figure 24 that acoustic emissions or microcracking first occurs near the four corners. With the increase of loading, acoustic emissions propagate across the pillar. At the same time, microcracks lead to the formation of a shear band across the pillar.

Suorineni et al. $[9,10]$ asked if the empirical pillar strength formulas are still applicable to pillars subjected to shear 

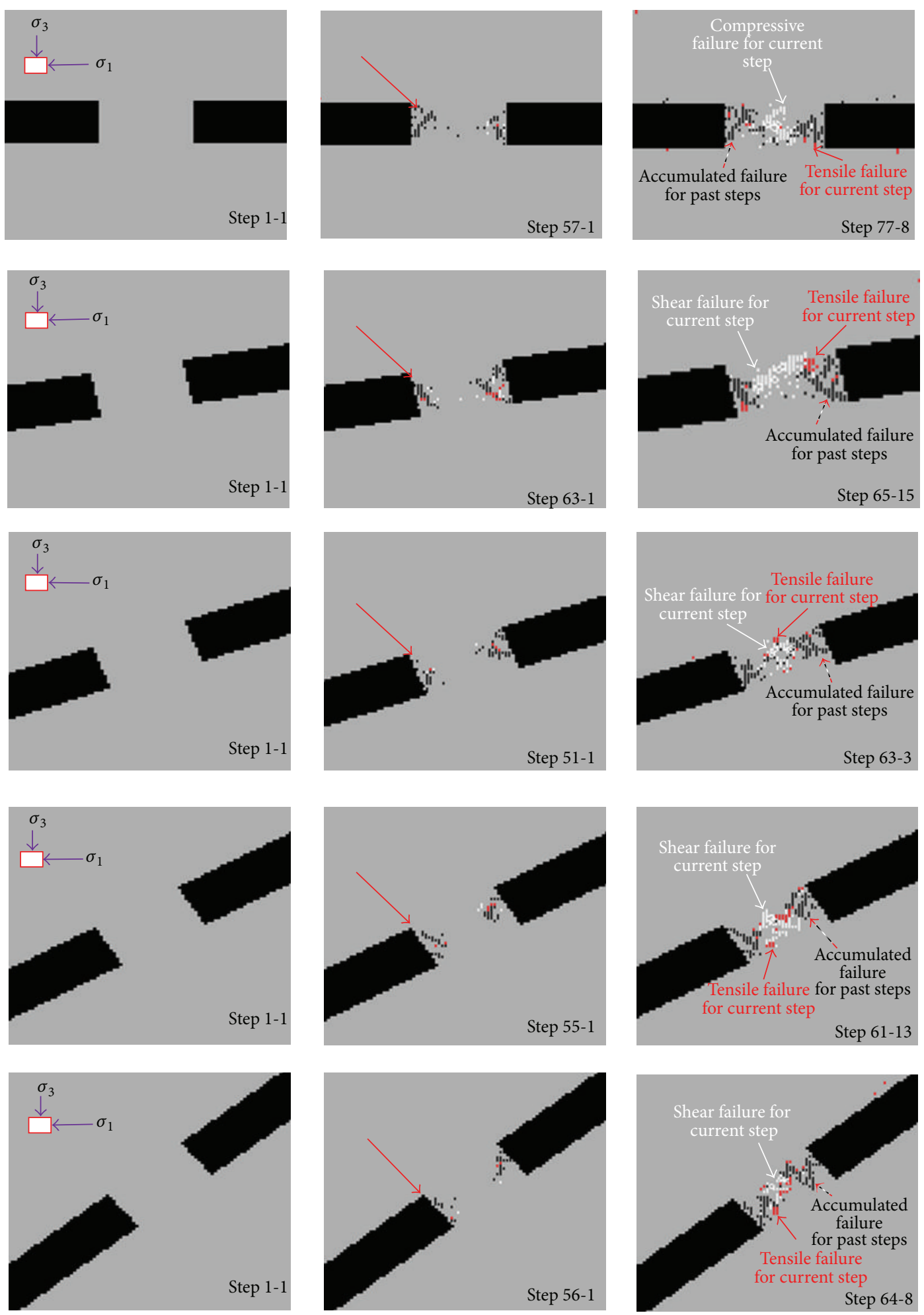

Figure 24: Acoustic emissions in the pillar when the dip angle is between $0^{\circ}$ and $40^{\circ}$.

loading. The empirical pillar strength formulas for hard rocks are shown in Table 2.

$W$ is the pillar width, $H$ is the pillar height, $\sigma_{c}$ is the uniaxial compressive strength of the pillar intact rock, and $\sigma_{\mathrm{rm}}$ is the pillar rock mass strength.
Why inclined pillars are more prone to shear failure? In Figure 25, $\sigma_{1}$ can be decomposed into the axial stress perpendicular to the pillar surface, $\sigma_{1} \cos \theta$ ( $\theta$ is the dip angle of the pillar) and the shear stress acting downward along the pillar surfaces, $\sigma_{1} \sin \theta$. As the pillar is under 
TABLE 2: Empirical formulae for hard rock pillar strength.

\begin{tabular}{ll}
\hline Empirical formula & Reference \\
\hline$\sigma_{\mathrm{rm}}=133 \frac{W^{0.5}}{H^{0.75}}$ & \\
$\sigma_{\mathrm{rm}}=65 \frac{W^{0.46}}{H^{0.66}}$ & \\
$\sigma_{\mathrm{rm}}=35.4\left(0.778+0.222 \frac{W}{H}\right)$ \\
$\sigma_{\mathrm{rm}}=0.42 \sigma_{c} \frac{W}{H}$ \\
$\sigma_{\mathrm{rm}}=74\left(0.778+0.222 \frac{W}{H}\right)$
\end{tabular}

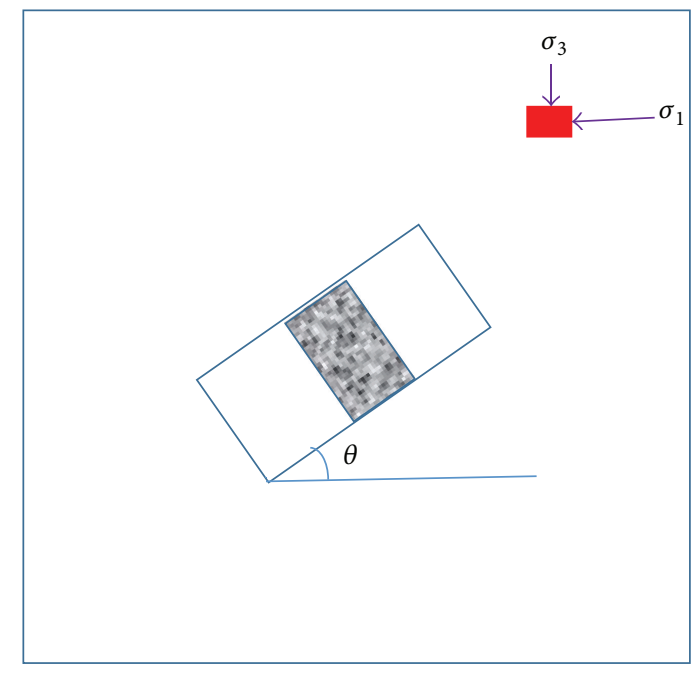

FIGURE 25: Direction of $\sigma_{1}$ acting on the pillar at various angles.

compression, its bearing capacity is enhanced. The shear stress acting downward along the pillar surface is a driving force for sliding. The overall shear resistance of the pillar is $\tau=c+\sigma_{1} \cos \theta \tan \varphi-\sigma_{1} \sin \theta$ ( $\varphi$ is the angle of internal friction). It indicates that the pillar is more prone to shear failure when the dip angle is greater. This is in agreement with the simulation results by RFPA2D.

4.4. Verification of Numerical Results against Field Data. As illustrated in Figure 26 most of failed pillars lie within the 0.51.5 width-to-height ratio. It is also noticeable that there are few recorded failed pillars with width-to-height ratio greater than two. Looking at field data very similar trend can be observed. Therefore, the application of empirical formulas is limited to the width-to-height ratios smaller than two. Actually, the empirical curves [28] have wrong trends after width-to-height ratio greater than two. If considering this issue by limit analysis method, the average pillar stress would be infinite, as width-to-height ratio reaches infinite and does not keep a constant like empirical curves.

4.5. Stress Distribution of Failure Process due to Excavation. In order to demonstrate the stress distribution of room excavation and pillar failure process, two groups of models were built with inhomogeneous and homogeneous materials

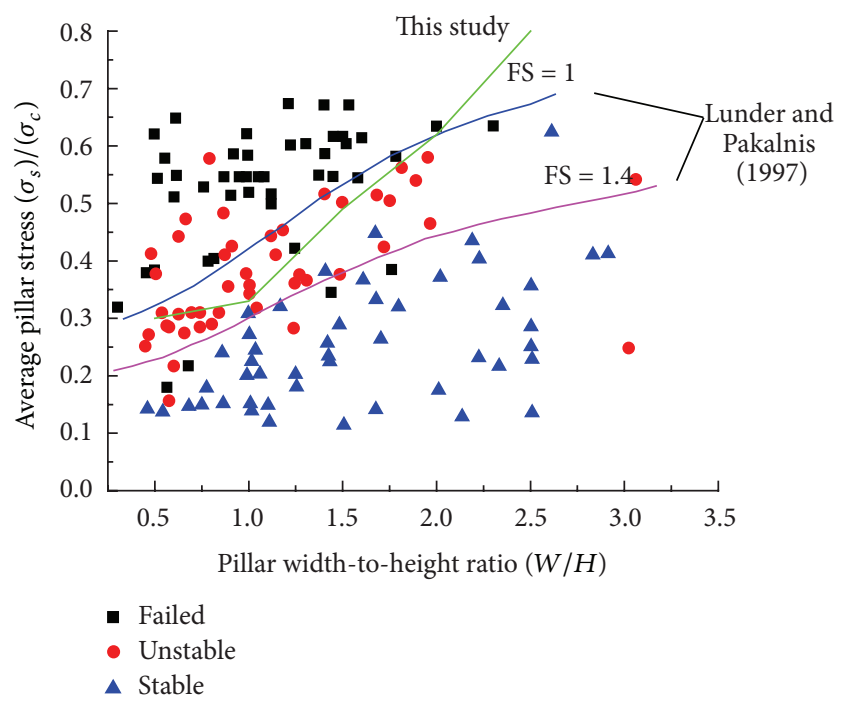

FIGURE 26: The study result superimposed on Lunder and Pakalnis [28] empirical design chart.

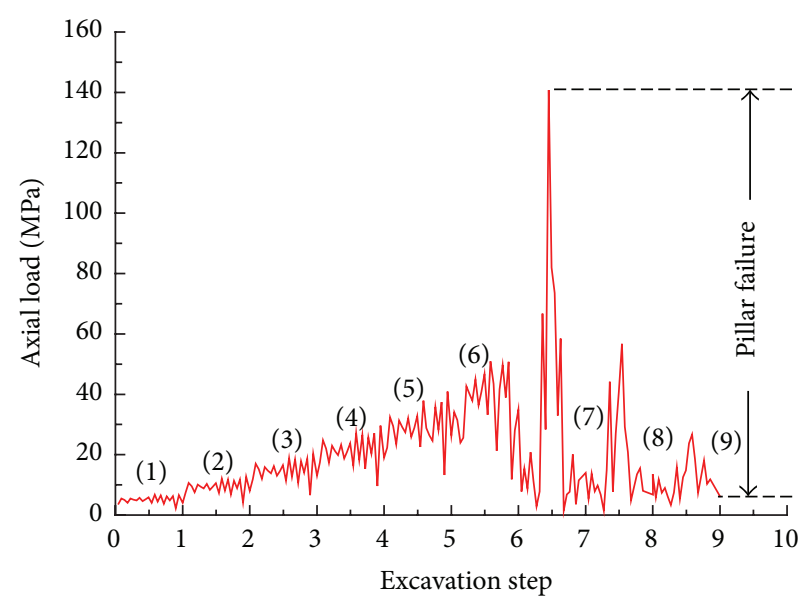

FIgURE 27: Pillar load history as a function of excavation step.

under certain loading condition with the factor of safety less than 1.0. It is easy to observe the failure process during the excavation. The data from Figures 27 to 30 were derived from the midheight of pillar as shown in Figure 4.

(1) For Inhomogeneous Rock Materials $(m=4)$. Rock is a kind of inhomogeneous material which embedded much structure planes. Under the external loading, the macroscopical deformation and failure characteristics for rock were determined by the interaction of crack initiation, crack propagation, and crack coalescence. We define $m$ as the homogeneity index of the rock, which satisfied Weibull distribution. A larger value of $m$ represents a more homogeneous material and vice versa [29].

Figure 27 illustrated the pattern of stress change within the pillar during the excavation process for width-to-weight ratio equal to 1.5. It can be seen from this figure that, in mining step 7, pillar load drops noticeably indicating the pillar failure. Figure 28 showed the maximum principal stress in the pillars 


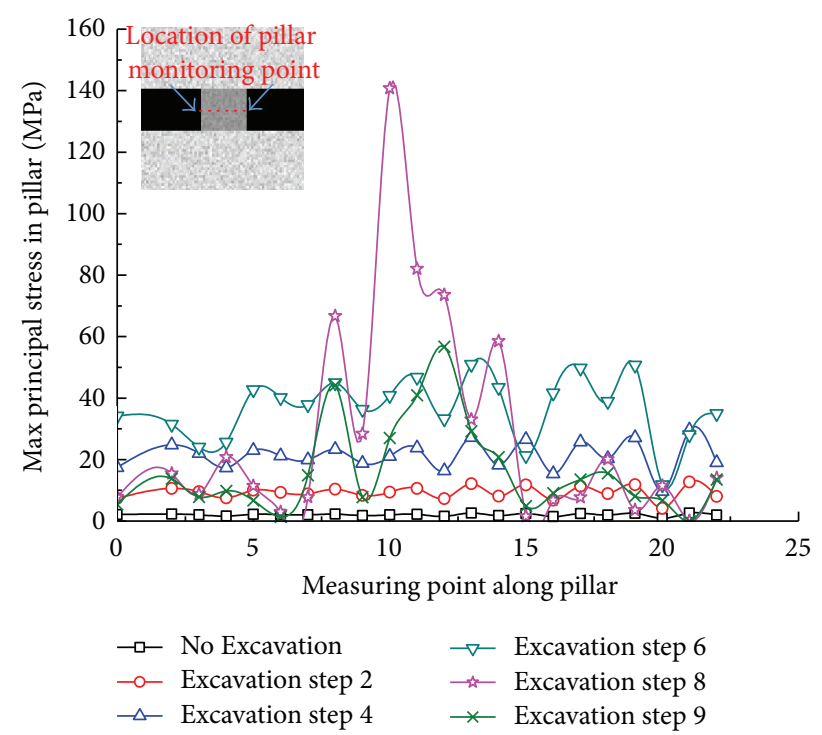

Figure 28: Pattern of stress change within the pillar during the excavation process, $W / H=1.5$.

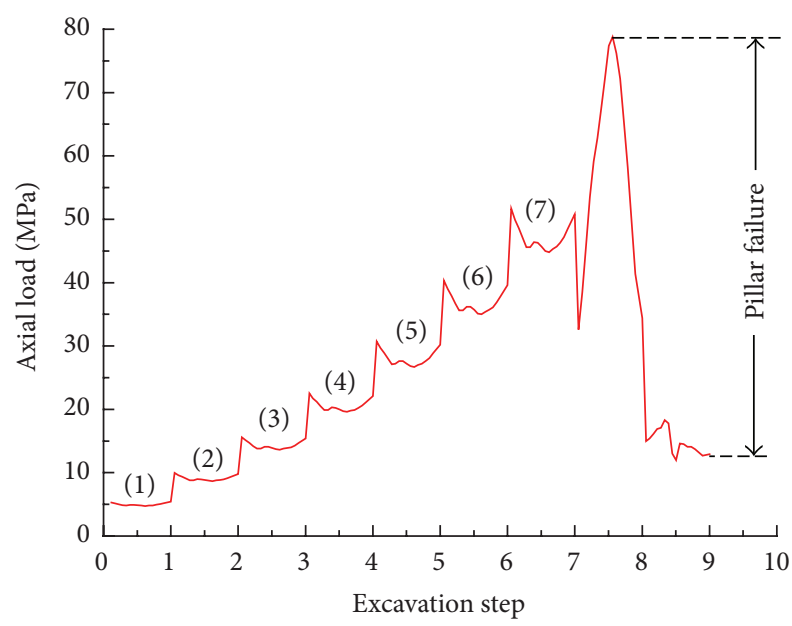

Figure 29: Pillar load history as a function of excavation step.

during excavation process. As can be seen from the figure, before excavation, the magnitude of maximum principal stress is equal to the in situ principal stress. As excavation started on both sides of pillar, the maximum principal stress started to build up at the edges of pillars. This is followed by the pillar edge failure leading to stress concentration shifting towards the pillar core (shown in Figure 28 step 7). Pillar core failure implied that the entire pillar lost its support capacity and the stress decreased sharply (shown in Figure 28 step 9).

(2) For Homogenous Rock Materials $(m=100)$. Figures 29 and 30 have the same trend with Figures 27 and 28, however, which curves keep more smoother. Moreover, since homogeneous materials were adopted in this case, stress concentration is insignificant and peak value of curves is less than inhomogeneous materials cases.

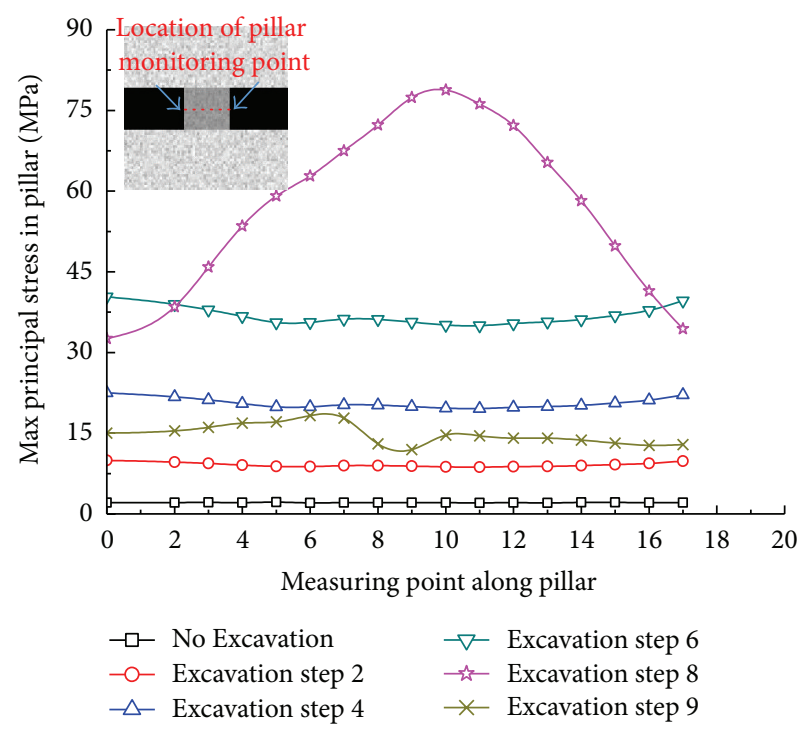

FIGURE 30: Pattern of stress change within the pillar during the excavation process, $W / H=1.5$.

\section{Conclusions}

By simulating the failure process of pillars with different dip angles and the stress ratio $k_{o}$ using the rock failure process analysis program, the following conclusions can be drawn:

(1) Shear failure often occurs in orebody under shear loading. The failure of pillars subject to shear stresses is related to the increase of the pressure ratio $k_{o}$ and the increase of brittleness.

(2) The application of empirical formulas is limited to the width-to-height ratios smaller than two. Actually, the empirical curves [28] have wrong trends after widthto-height ratio greater than two, as most empirical design charts and formulas for pillars only consider the axial strength and neglect insufficiency in shear strength. Hence, they are not applicable for orebody under shear loading.

(3) In a dipping orebody, $\sigma_{1}$ acts on the orebody similar to gravity. It has an obliquely downward component. As a result, the pillar under shear stress is more prone to failure. Therefore, the angle between $\sigma_{1}$ and the orebody is another factor for pillar rock bursts.

(4) With increasing dip angle of the pillar, stress concentration first appears at the four corners, leading to microcracking. As the stress in the pillar continuously increases, microcracks gradually coalesce. Subsequently, shear band occurs across the pillar and failure occurs. Therefore, it is inappropriate to neglect the corner stresses for determination of average stress in the pillar.

(5) The pattern of stress changes within the pillar as excavation proceeds. Elastic stresses start to build up at the pillar edges and stress concentration rises at these points, and the pillar edge failure leads to stress 
concentration shifting towards the pillar core. The heterogeneity of rock material has an effect on the pattern of stress concentration in pillars.

\section{Competing Interests}

The authors declare that they have no competing interests.

\section{Acknowledgments}

This research work was supported by the Chinese National Key Basic Research Development Plan (973) (Grant no. 2014CB047100), the Science Fund for Creative Research Groups of the National Natural Science Foundation of China (Grant no. 51421064), and the Chinese National Natural Science Foundation (Grant no. 41572249).

\section{References}

[1] B. G. H. Brady and E. T. Brown, Rock Mechanics for Underground Mining, Allen \& Unwin, Boston, Mass, USA, 1985.

[2] Z. T. Bieniawski, "The effect of specimen size on compressive strength of coal," International Journal of Rock Mechanics and Mining Sciences and, vol. 5, no. 4, pp. 325-335, 1968.

[3] P. J. Lunder and R. C. Pakalnis, "Determination of the strength of hard-rock mine pillars," World Mining Express, vol. 4, pp. 2428, 1998.

[4] C. González-Nicieza, M. I. Álvarez-Fernández, A. MenéndezDíaz, and A. E. Álvarez-Vigil, "A comparative analysis of pillar design methods and its application to marble mines," Rock Mechanics and Rock Engineering, vol. 39, no. 5, pp. 421-444, 2006.

[5] G. S. Esterhuizen, "An evaluation of the strength of slender pillars," in Transactions of Society for Mining, Metallurgy, and Exploration, W. R. Yernberg, Ed., vol. 320, pp. 69-76, Society for Mining, Metallurgy, and Exploration, Littleton, Colo, USA, 2006.

[6] A. Mortazavi, F. P. Hassani, and M. Shabani, "A numerical investigation of rock pillar failure mechanism in underground openings," Computers and Geotechnics, vol. 36, no. 5, pp. 691697, 2009.

[7] G. S. Esterhuizen, D. R. Dolinar, and J. L. Ellenberger, "Pillar strength in underground stone mines in the United States," International Journal of Rock Mechanics and Mining Sciences, vol. 48, no. 1, pp. 42-50, 2011.

[8] E. Ghasemi and K. Shahriar, "A new coal pillars design method in order to enhance safety of the retreat mining in room and pillar mines," Safety Science, vol. 50, no. 3, pp. 579-585, 2012.

[9] F. T. Suorineni, P. K. Kaiser, J. J. Mgumbwa, and D. Thibodeau, "Mining of orebodies under shear loading part 1-case histories," Mining Technology: Transactions of the Institutions of Mining and Metallurgy: Section A, vol. 120, no. 3, pp. 137-147, 2011.

[10] F. T. Suorineni, J. J. Mgumbwa, P. K. Kaiser, and D. Thibodeau, "Mining of orebodies under shear loading part 2-failure modes and mechanisms," Mining Technology: Transactions of the Institutions of Mining and Metallurgy Section A, vol. 123, no. 4, pp. 240-249, 2014.

[11] M. Y. Liu and C. Y. Xu, "Stability analysis of pillars in minedout area," Mining and Metallurgical Engineering, vol. 20, no. 1, pp. 20-22, 2000.
[12] M. C. Yang, "Study on size design method of pillars," Mining Technology, vol. 5, no. 3, pp. 10-12, 2005.

[13] Z. Q. Wang and H. F. Li, "Numerical calculation method for shear safety coefficient of mine pillar," Journal of Mining \& Safety Engineering, vol. 27, no. 2, pp. 277-280, 2010.

[14] X. J. Wang, X. Feng, T. B. Yang, K. Zhao, and K. Zhao, "Reasonable width calculation and analysis of artificial pillar in deep mining," Journal of Mining \& Safety Engineering, vol. 29, no. 1, pp. 54-59, 2012.

[15] E. Ghasemi, M. Ataei, and K. Shahriar, "An intelligent approach to predict pillar sizing in designing room and pillar coal mines," International Journal of Rock Mechanics \& Mining Sciences, vol. 65, pp. 86-95, 2014.

[16] Y. H. Li, S. Q. Nan, X. D. Zhao et al., "Stability of boundary pillars for transition from open pit to underground mining," Chinese Journal of Rock Mechanics and Engineering, vol. 24, no. 2, pp. 278-283, 2005.

[17] Y. W. Zhong, W. Wan, Y. L. Zhao et al., "Safety pillar thickness determination and local monitoring in Wengfu phosphate," Mineral Engineering Research, vol. 27, no. 3, pp. 28-33, 2012.

[18] C. Tang, "Numerical simulation of progressive rock failure and associated seismicity," International Journal of Rock Mechanics and Mining Sciences, vol. 34, no. 2, pp. 249-261, 1997.

[19] C. A. Tang and S. Q. Kou, "Crack propagation and coalescence in brittle materials under compression," Engineering Fracture Mechanics, vol. 61, no. 3-4, pp. 311-324, 1998.

[20] C. A. Tang, W. T. Yang, Y. F. Fu, and X. H. Xu, "A new approach to numerical method of modelling geological processes and rock engineering problems-continuum to discontinuum and linearity to nonlinearity," Engineering Geology, vol. 49, no. 3-4, pp. 207-214, 1998.

[21] C. A. Tang and P. K. Kaiser, "Numerical simulation of cumulative damage and seismic energy release in unstable failure of brittle Rock-part I. Fundamentals," International Journal of Rock Mechanics and Mining Sciences, vol. 35, no. 2, pp. 113-121, 1998.

[22] H. Y. Liu, M. Roquete, S. Q. Kou, and P.-A. Lindqvist, "Characterization of rock heterogeneity and numerical verification," Engineering Geology, vol. 72, no. 1-2, pp. 89-119, 2004.

[23] M. C. He, J. L. Miao, and J. L. Feng, "Rock burst process of limestone and its acoustic emission characteristics under truetriaxial unloading conditions," International Journal of Rock Mechanics \& Mining Sciences, vol. 47, no. 2, pp. 286-298, 2010.

[24] G. Manthei and J. Eisenblätter, "Acoustic emission in study of rock stability," in Acoustic Emission Testing, C. U. Grossc and M. Ohtsu, Eds., pp. 239-310, Springer, Berlin, Germany, 2008.

[25] G. Q. Chen, T. B. Li, G. F. Zhang, H. Yin, and H. Zhang, "Temperature effect of rock burst for hard rock in deep-buried tunnel," Natural Hazards, vol. 72, no. 2, pp. 915-926, 2014.

[26] M. F. Cai, Rock Mechanics and Engineering, Science Press, Beijing, China, 2013.

[27] E. Hoek and E. T. Brown, "Empirical strength criterion for rock masses," Journal of the Geotechnical Engineering Division ASCE, vol. 106, no. GT9, pp. 1013-1035, 1980.

[28] P. J. Lunder and R. C. Pakalnis, "Determination of the strength of hard-rock mine pillars," Canadian Institute of Mining Bulletin, vol. 90, no. 1013, pp. 51-55, 1997.

[29] C. A. Tang, L. G. Tham, S. H. Wang, H. Liu, and W. H. $\mathrm{Li}$, "A numerical study of the influence of heterogeneity on the strength characterization of rock under uniaxial tension," Mechanics of Materials, vol. 39, no. 4, pp. 326-339, 2007. 
[30] D. G. F. Hedley and F. Grant, "Stope-and-pillar design for the Elliot Lake Uranium mines," Bulletin of the Canadian Institute of Mining and Metallurgy, vol. 65, pp. 37-44, 1972.

[31] M. R. Von Kimmelmann, B. Hyde, and R. J. Madgwick, "The use of computer applications at BCL limited in planning pillarm extraction and design of mining layouts," in Proceedings of the ISRM Symposium: Design and Performance of Underground Excavations, E. T. Brown and J. A. Hudson, Eds., pp. 53-63, British Geotechnical Society, Cambridge, UK, September 1984.

[32] N. Krauland and P. E. Soder, "Determining pillar strength from pillar failure observations," Engineering \& Mining Journal, vol. 8, pp. 34-40, 1987.

[33] Y. Potvin, M. R. Hudyma, and H. D. S. Miller, "Design guidelines for open stope support," Bulletin of the Canadian Institute of Mining and Metallurgy, vol. 82, pp. 53-62, 1989.

[34] J. Sjoberg, "Failure modes and pillar behaviour in the Zinkgruvan mine," in Proceedings of 33rd U.S. Rock Mechanics Symposium, J. A. Tillerson and W. R. Wawersik, Eds., pp. 491-500, A. A. Balkema, Rotterdam, The Netherlands, 1992. 


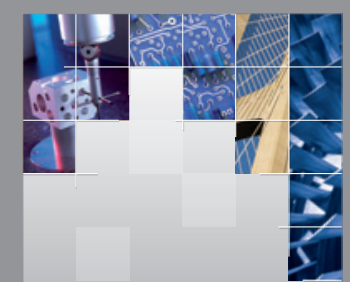

\section{Enfincering}
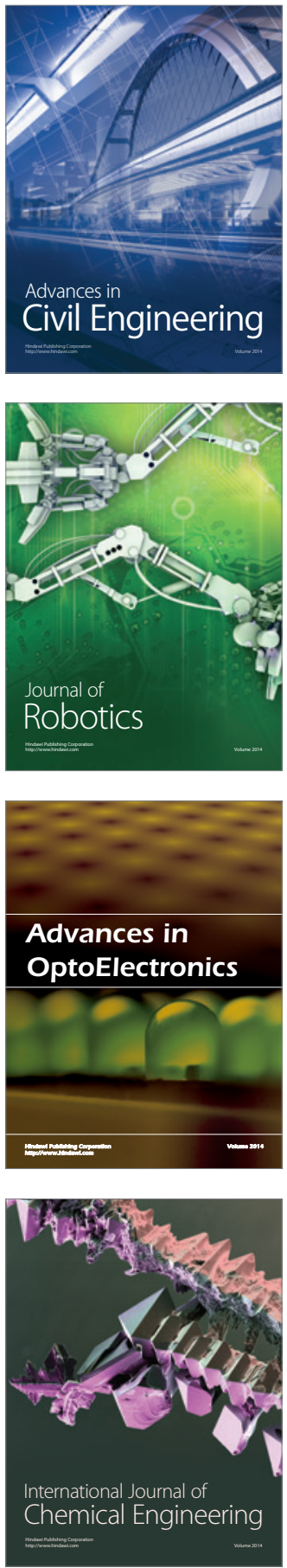

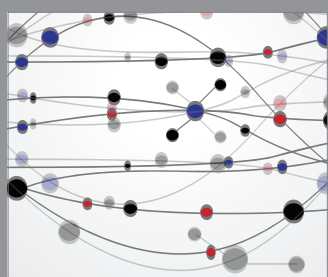

The Scientific World Journal

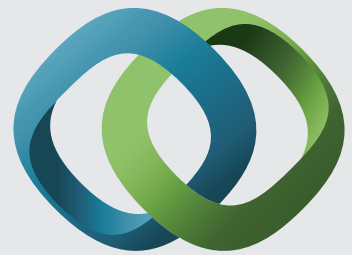

\section{Hindawi}

Submit your manuscripts at

http://www.hindawi.com
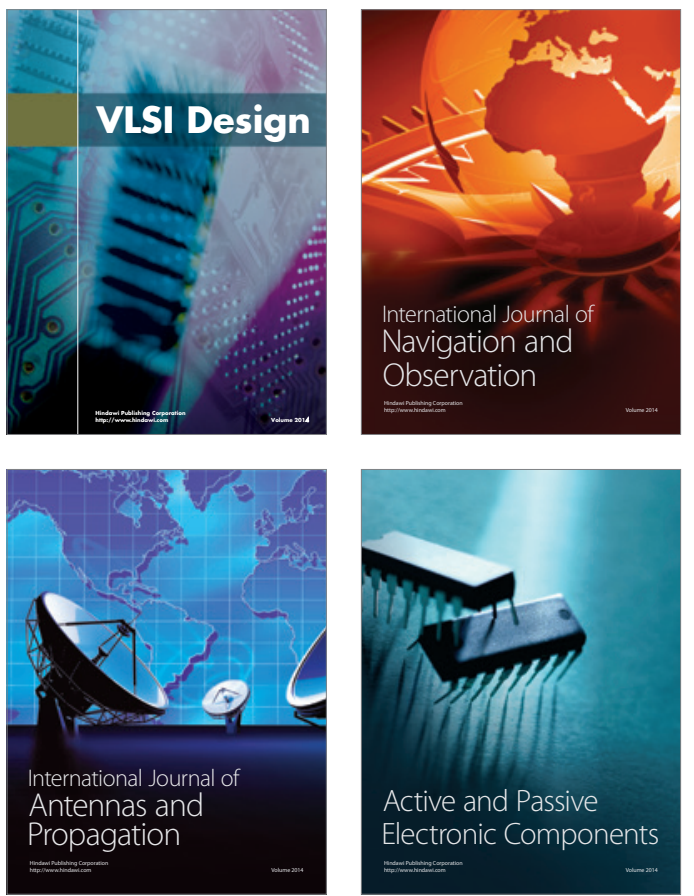
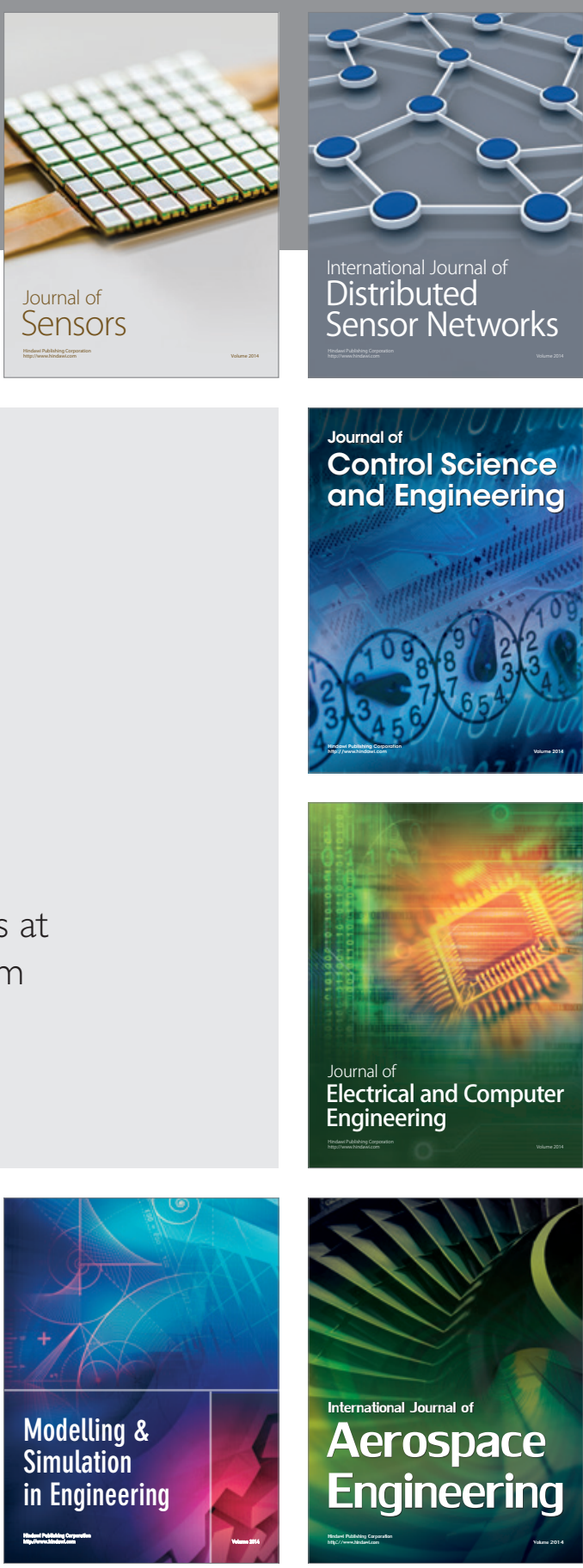

International Journal of

Distributed

Sensor Networks

Journal of

Control Science

and Engineering
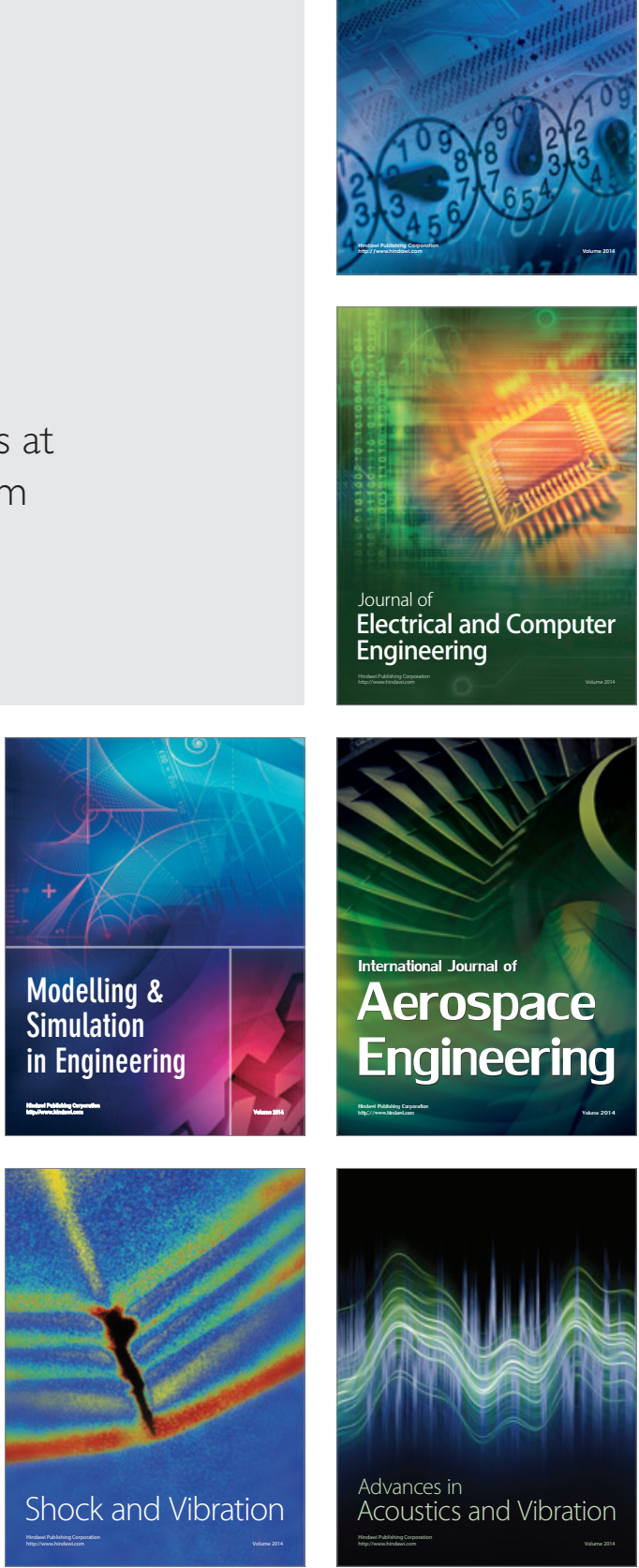